\title{
Mentoring Graduate Students to Become Effective Teaching Assistants: Developing and Implementing a Student-Centred Program for Nursing
}

\author{
Genevieve M. Breau \\ University of British Columbia, genevieve.breau@alumni.ubc.ca \\ Suzanne H. Campbell \\ University of British Columbia, suzanne.campbell@ubc.ca \\ Carla Hilario \\ University of Alberta, carla.hilario@ualberta.ca \\ Catherine L. Goldie \\ Queen's University, katie.goldie@queensu.ca \\ Jennifer N. Auxier \\ University of Turku, jennifer.n.auxier@utu.fi \\ Bernie Garrett \\ University of British Columbia, bernie.garrett@ubc.ca \\ Colleen Varcoe \\ University of British Columbia, colleen.varcoe@ubc.ca
}

Follow this and additional works at: https://qane-afi.casn.ca/journal

Part of the Nursing Commons

\section{Recommended Citation}

Breau, Genevieve M.; Campbell, Suzanne H.; Hilario, Carla; Goldie, Catherine L.; Auxier, Jennifer N.; Garrett, Bernie; and Varcoe, Colleen (2020) "Mentoring Graduate Students to Become Effective Teaching Assistants: Developing and Implementing a Student-Centred Program for Nursing," Quality Advancement in Nursing Education - Avancées en formation infirmière: Vol. 6: Iss. 3, Article 3.

DOI: https://doi.org/10.17483/2368-6669.1206

This Article is brought to you for free and open access by Quality Advancement in Nursing Education - Avancées en formation infirmière. It has been accepted for inclusion in Quality Advancement in Nursing Education - Avancées en formation infirmière by an authorized editor of Quality Advancement in Nursing Education - Avancées en formation infirmière. 
A Nursing faculty shortage are not a new phenomenon (Winston, 2011). Demands for doctorally prepared nursing faculty have increased because of the shortages and because of the climbing faculty age, wave of faculty retirements, and higher compensation in clinical and privatesector settings. Data from the United States shows a 7.9\% national vacancy rate for nursing faculty, with $90.7 \%$ of those vacancies requiring or preferring a doctoral degree (Li et al., n.d.). In Canada, the Canadian Nurses Association (n.d.) projects a shortage of 60,000 nurses by the year 2022. Other factors affecting nursing shortages and the ability to educate the next generation include limited classroom spaces and clinical sites, and a need for emerging and interactive technologies to transform how we teach. These factors have created a demand for educators to offer innovative and flexible teaching methods in undergraduate education (Cheng et al., 2016; Murray, 2018; Sheng et al., 2019; Ward et al., 2018). Within this context, it has become evident that providing mentoring opportunities for the next generation of nursing educators is necessary (Murray, 2018). Nursing programs' focus on developing students' clinical practice and research skills, evidencebased practice, and professional behaviours leave little room in the curriculum for acquiring instructional skills that translate to classroom settings (Murray, 2018). In addition, in health professional programs such as nursing, nursing educators are expected to teach not only in classroom settings but also in clinical settings. Consequently, graduate students are often ill prepared to serve as teaching assistants (Blouin \& Moss, 2015) and may not be well equipped for future careers in academia or to effectively mentor and teach in clinical settings. The purpose of this paper is to describe an innovative approach to mentoring graduate students to develop their teaching skills.

\section{Purpose}

First, the gap in published research regarding the preparation of graduate nursing students for careers in academia is explored. Next, a description is provided of how teachers at a western Canadian university school of nursing developed a graduate teaching assistant (GTA) mentorship program to help address this issue and give graduate students the skills and experience to succeed in academia in one of the key areas of teaching success. Finally, the evolution of our GTA mentorship program over the past eight years is outlined, including adaptations that were made to meet GTAs' diverse needs as the setting and content of the classroom environment changed over time.

\section{Background Literature}

Most of the published descriptions of GTA professional development programs outline department-specific teaching programs, are often published from smaller universities in the United States, and frequently focus on the sciences or the social sciences. The programs described in these publications focus on professional development of GTAs to provide assistance in large undergraduate classes in engineering (Crede et al., 2010), chemistry (Dragisich et al., 2016; Pentecost et al., 2012), mathematics (Harris et al., 2009; Moore, 2005), and kinesiology (Russell, 2008), which all have significant laboratory components. The emphasis in these papers is frequently on staffing and ensuring that appropriate scientific information is transmitted to students, rather than on taking a proactive approach to preparing graduate students for academic teaching careers (Dragisich et al., 2016; Pentecost et al., 2012).

The papers published in the social sciences place a greater emphasis on preparation for future postsecondary teaching. For example, a psychology graduate teaching program used socialcognitive theories to increase graduate students' self-efficacy regarding teaching (Komarraju, 
2008). However, authors in counselling psychology (Prieto \& Scheel, 2008) and sociology (Blouin \& Moss, 2015) have noted that there is, in some cases, limited pedagogical/andragogical professional development for graduate students, even though many want to pursue teaching careers in academia.

Little has been published regarding such preparation in nursing. Chandler (2005) examined a professional development program in nursing to prepare undergraduate nursing students to work with GTAs and faculty in teaching large, undergraduate courses. This program involved both GTAs and second-year undergraduate students. Faculty mentored GTAs on the co-development of learning materials and assessment methods, as well as mentoring undergraduate students in a leadership class to lead discussion groups and mentor first-year students. This descriptive report provided support for collaborative mentoring at different levels, respecting the experiences and expertise of all involved, and identified the benefits in leadership development of students at all stages (Chandler \& Genevieve, 2005). This is the only report found regarding graduate student educational mentoring in nursing, demonstrating the gap in the reporting of GTA nursing professional development programs.

\section{Context}

\section{Educational Programs}

The site for this work was a school of nursing located in western Canada that offers undergraduate and graduate professional development in nursing, including an undergraduate bachelor of science in nursing $(\mathrm{BScN})$ two-year advanced standing baccalaureate, a master of science in nursing (MSN), a master of nursing-nurse practitioner (MN-NP), and a PhD in nursing programs. All programs are highly competitive and prepare students to enter the clinical profession of nursing (BScN), become advanced practice nurses (MSN/MN-NP), and/or become clinician scientists and researchers $(\mathrm{PhD})$ in nursing.

The $\mathrm{BScN}$ program is a full-time 24-month program and includes both coursework and clinical, experiential learning in nursing. The MSN program is full or part time for a minimum of 24 months, and requires both clinical and research coursework and a research thesis or scholarly project. The MN-NP program is a full-time 24-month program that includes clinical coursework and professional development and prepares candidates to apply for licensure as nurse practitioners. The PhD program is a minimum of 36 months and requires coursework, comprehensive examinations, an oral examination, and a research-based dissertation that makes a unique contribution to literature in one's doctoral research field.

\section{Rationale for a Graduate Teaching Assistant Mentoring Program}

As most nursing PhD graduates (and many master's graduates) aim to pursue faculty positions at postsecondary institutions that include teaching responsibilities, and in light of the upcoming shortage of nursing faculty (Li et al., n.d.; Winston, 2011), there is a need to mentor graduate students in this important area. In response to an enhanced focus in university policies on increasing graduate student financial support, the school developed and implemented a GTA mentoring program in 2011.

The original aim of the GTA program was to provide support to faculty in teaching, but over time, it became apparent that providing graduate nursing students with structured professional development opportunities to gain experience in educational strategies specific to nursing, while being mentored by expert postsecondary educators, was a worthwhile endeavour. Moreover, 
including a professional development component in the GTA mentoring program assisted graduate students in their career preparation.

\section{Educational Theories Underlying the GTA Mentorship Program}

In designing the GTA Mentorship program, three student-centred educational theoretical perspectives were adopted to ensure that the program developed the needs of the students and was appropriate to their practice as GTAs. Experiential learning, andragogy, and social learning theory were used as the context for this development (Garrett, in press).

Experiential learning is a theoretical perspective frequently used in adult educational programs, developed by David Kolb in 1974. This model posits that there are four elements in a cycle through which learners move when acquiring new knowledge or a new skill: perceiving a new experience, observing and reflecting on the experience, forming abstract concepts based on the observation, and testing the new concept (Kolb \& Fry, 1974). We used this theory on the premise that GTAs would learn best practices through doing, and the program was structured around giving instruction regarding best practices at each stage of the mentorship program, allowing GTAs to apply these strategies as part of their teaching practice, and then having them return and discuss their experiences with their peers.

Andragogy was used as a second theoretical perspective in the work as it provided a humanistic perspective. The theory was developed by Malcolm Knowles, who suggested five assumptions in adult education that differentiate it from pedagogy, which is used by childhood educators: (1) the need to know, (2) the learning self-concept, (3) the role of learners' experience, (4) the readiness to learn; and (5) the orientation to learning (Knowles, 1984). In our GTA mentorship program planning, we emphasized the readiness to learn as a key aspect, in that all GTAs were eager to learn the strategies, skills, and knowledge they required to become effective GTAs and teachers of adult learners, and were keen to apply new skills and knowledge in their teaching practice. We determined which skills were seen as essential by consulting both faculty and GTAs from prior years and developing new educational sessions each year based on the stated needs.

The third theoretical perspective that was applied incorporated social learning theory, in the form of situated learning theory, as developed by Jean Lave and Etienne Wenger in 1990 (Lave \& Wenger, 1990). It is a theory that is frequently used in nursing education and corresponds to a collaborative approach to teaching and learning. Lave and Wenger posit that communities of practice, in which practitioners, such as GTAs, gather in peer groups to exchange information and knowledge, assist with becoming an accepted practitioner in the field. Because of this perspective, we focused on the experiential aspect of learning how to be an effective nursing educator and promoted group discussion at each GTA training session to generate collegiality between peers and more experienced teachers. In these sessions, more experienced GTAs shared their experiences and perspectives, and novice GTAs voiced their concerns and worries about teaching.

In addition to the three educational theories, we drew on the concept of cultural safety, as described by Papps and Ramsden (1996), in planning and delivering the GTA program. This concept underpinned several components of the preparing that was integrated to meet the learning needs of the students and the GTAs. Cultural safety was identified as a critical concern within the school, the university, and the broader Canadian context of reconciliation (Truth and Reconciliation Commission of Canada. n.d.). 


\section{Structure of the GTA Mentorship Program}

The GTA program was developed to prepare nurse scientists for teaching careers in academia. This program has evolved over the years to meet emerging needs that have arisen during the program. GTAs are required to be currently enrolled graduate students (i.e., in the MSN, MN$\mathrm{NP}$, or PhD programs). The rationale is that they have a sufficient understanding of nursing; GTAs are required to be capable of undertaking graduate-level work. Another intention of this requirement is to minimize the risk that GTAs are classmates or peers with the students for whom they are responsible in teaching, as only $\mathrm{PhD}$ students are assigned to MSN and MN-NP classes (either $\mathrm{PhD}$ or $\mathrm{MSN} / \mathrm{MN}-\mathrm{NP}$ may be assigned to $\mathrm{BScN}$ courses). Courses to which GTAs are assigned include undergraduate research methods and statistics courses; undergraduate theoretical, clinical, and lab courses; graduate courses in statistics; and undergraduate and graduate courses on the theoretical underpinnings of nursing practice and research. Clinical and lab courses are taught by contract instructors who receive separate professional development support within the department for clinical instruction at this school of nursing located in western Canada.

At this school of nursing located in western Canada, GTAs are assigned to both large undergraduate courses $(n=120)$ and smaller graduate courses $(n=12-30)$, requiring a variety of skill sets, and they perform duties beyond marking and assessment. They assist with curriculum development, contribute to assessment guidelines, hold student seminars, engage with students in online and face-to-face classroom learning environments, reply to email queries, and host office hours. Furthermore, GTAs are also expected to develop and deliver at least one guest lecture per course. This guest lecture is considered essential for the GTA position as it gives graduate students direct teaching experience with support, direction, and feedback provided by their faculty lead.

A senior teaching assistant (TA) position has been established as a role designed to enhance the incumbent's teaching, leadership, and professional experience, as well as to act as a formal mentor to the other GTAs. Senior TAs also coordinate the development and delivery of the GTA mentorship program throughout the year. This process includes conducting formal and informal needs assessments with GTAs and faculty, choosing the most relevant topics during professional development, and organizing the logistics for professional development. The senior TA must have held a GTA-ship for a minimum of 12 months and demonstrated success both as a GTA and in a leadership role, and the appointment involves a competitive application process overseen by the director and the outgoing senior TA. The senior TA receives direct mentorship from the director of the school and collaborates with the university resources for teaching and student learning to develop programming for a one-year term. For example, the senior TA works with the director to develop and submit an internal university grant application to fund professional development activities; coordinates the delivery of the professional development program; prepares a year-end report, including both a financial statement and an assessment of how the program's goals were achieved; and makes recommendations for the following year. The senior TA is compensated up to 20 hours per term, at the same rates as a GTA, for the work involving mentorship, planning, and delivery of the professional development activities, and these funds are from the School of Nursing TA budget.

A faculty GTA liaison is also appointed as a direct support for GTAs in the school. The person in this position is an experienced member of faculty who does not have any GTAs in their course portfolio for the year of appointment and provides support and guidance to all GTAs as necessary. The faculty liaison and the senior TA collaborate and make themselves available to all GTAs for impartial advice on academic, educational, and practical matters. 


\section{The School of Nursing GTA Mentorship Program}

At Canadian postsecondary institutions, many GTA professional development programs are offered through a centralized service accessible to GTAs employed in all disciplines. This university uses a different approach where a central teaching centre (Centre for Teaching, Learning, and Technology [CTLT]) provides individualized support for TA programs tailored to specific departmental needs. To offset the costs of offering the department-specific professional development, a central university source (Office of the Vice-Provost and Vice President Academic) provides competitive funds for which departmental TA programs may apply to enhance their learning, such as hiring professional workshop facilitators employed by the central teaching centre.

The GTA professional development program at our School of Nursing has existed in its current form since the 2011-2012 academic year. It consists of a required orientation, topicspecific sessions throughout the academic year, informal feedback sessions on the successes and areas for improvement for professional development, and additional specialized professional development, including topics such as cultural safety and educational strategies. The orientation typically occurs before classes start at the beginning of the academic year (late August-early September); one session occurs midway through the fall term; and the second session occurs midway through the winter term. One of these two sessions examines cultural safety, although the term in which the session is provided may change each year. These activities are supported by the School of Nursing TA Handbook, which is used as a resource by GTAs throughout the academic year.

The School of Nursing GTA Handbook. The School of Nursing GTA Handbook was developed by the senior TA in the 2013-2014 academic year, in collaboration with the School of Nursing director. It contains information about BScN and MSN programs, contact information for key faculty and course leaders, resources for GTAs, and links to relevant School of Nursing policies, such as information about the school's grading and assessment criteria and assignment submission policies. The contact information for faculty and course leaders is updated before the start of each academic year, and updated policies are included; otherwise, the majority of the content remains unchanged.

Orientation. The senior TA, in collaboration with the faculty liaison, staff, and other nursing faculty, organizes a 2-3-hour orientation for new and returning GTAs just before the start of the academic year, generally in late August or early September. This orientation is mandatory, and faculty, including the director and associate directors of the undergraduate and graduate programs, welcome GTAs and discuss the courses to which GTAs are assigned, explaining how these courses fit into the BScN and MSN curricula.

GTAs are also oriented to departmental-specific information, such as how to use the TA departmental office and how to book classrooms and technological and computer equipment in the department. Staff deliver important information regarding university policies on appropriate use of information technology (University, 2020) and access and privacy issues (University Board of Governors, 2020).

The university teaching assistant union executives deliver an information session. They provide important information regarding the union collective agreement and resources for GTAs. They also review information regarding GTA duties and responsibilities under the collective agreement (University \& Union, 2019). 
Finally, the senior TA delivers information regarding the GTAs' role in the department; summarizes the GTA handbook, specifically highlighting departmental policies for grading, assessment, and plagiarism; and provides further details regarding GTA's duties and responsibilities. Sufficient time is provided for questions and discussion to be sure incoming GTAs feel well supported and understand the expectations of their new roles. All GTAs, both new and returning, attend the orientation each year they are offered.

GTA Professional Development Seminars. In addition to the orientation at the start of the academic year, the senior TA organizes one to two seminars for GTAs per term, lasting 1-1.5 hours each. These sessions address a specific topic and are developed by the senior TA in collaboration with one or two facilitators at the CTLT. CTLT facilitators are graduate students from multiple departments who have additional professional development in workshop development and delivery.

Topics are chosen in collaboration with the senior TA, the director, the faculty liaison, and the GTAs and through consultation with experienced GTAs and faculty, and they are then developed and delivered by the senior TA and CTLT facilitators. Sessions are scheduled at the convenience of GTAs, and in recent years, faculty and clinical instructors have been invited to participate. The topics change each year in response to changing needs in the department, and both new and returning GTAs are expected to attend each session.

Past topics have included discussion of teaching philosophies and developing a teaching portfolio, technology in the classroom, cultural safety, and effective grading and marking techniques. The aim of the teaching philosophies session was to provide GTAs with tools to begin developing their teaching philosophy statements and portfolios for inclusion in faculty applications post-graduation. The technology session focused on using educational technology in large classroom settings, such as personal response systems (e.g., iClicker, Poll Everywhere), to facilitate classroom discussion and student involvement. The cultural safety session was a facilitated discussion led by staff from the CTLT's Indigenous Initiatives program and provided GTAs and faculty with tools to manage discussions regarding cultural safety in the classroom. Finally, the session on how to grade and mark student work effectively and efficiently was developed and led by a former senior TA (author 1), and facilitated a discussion of common methods, challenges, and ways of creating rubrics and other approaches to marking and assessment, as well as sharing examples from experienced GTAs. It is important to note that all GTAs are invited and expected to attend both sessions offered each year, and sessions are not offered on all topics described above each year.

Instructional Skills Workshop. For two years, funding for the TA mentorship program was also used to reserve spaces for GTAs in the university instructional skills workshop (ISW). The ISW is offered multiple times per year by CTLT and is an intensive, 24-hour, 3-day workshop designed to give graduate students pedagogical knowledge and experience delivering course lectures, with feedback from experienced facilitators and fellow graduate students. Given the long waitlist for this program, it was decided that reserving enrolment seats would allow more of the School of Nursing GTAs to participate in this program and gain formal instruction in educational strategies.

Education Regarding Cultural Safety. Cultural safety is an important part of the GTA professional development, both at the School of Nursing and in the larger university setting. The School of Nursing student body is very diverse in terms of age, ethnicity, socioeconomic 
background, and sexuality and gender expression. It is important that GTAs are provided professional development in terms of how to address such a diverse classroom setting.

Initially, the professional development program included the San'yas Indigenous Cultural Safety (ICS) professional development program offered through the Provincial Health Services Authority (2019). However, the majority of GTAs enroll in San'yas as part of their clinical work and it was seen as redundant. In addition, many of the GTAs expressed a desire to learn more about cultural safety with diverse groups, especially regarding gender and sexuality diversity. Finally, cultural safety in the classroom is different from cultural safety in a clinical setting (Browne et al., 2009; Browne et al., in press; Smye \& Browne, 2002; Varcoe \& Browne, 2015). Thus, while GTAs may be introduced to cultural safety in their clinical work, the skill set may not be immediately transferable to the classroom setting.

Accordingly, the senior TA collaborated with three expert facilitators from the CTLT's Indigenous initiatives program. A series of four case studies were developed: two based on scenarios GTAs might experience in a clinical teaching setting, and two based on classroom topics and activities that might elicit a challenge in terms of cultural safety. These latter two case studies were used to stimulate discussion surrounding cultural safety when these facilitators hosted a workshop at the School of Nursing. In 2015-2016, the workshop was attended by GTAs, faculty and clinical teaching staff at the school, while in 2016-2017, the workshop was attended by GTAs only. These case studies were successful in stimulating discussion regarding participants' own experiences with cultural safety in the classroom.

\section{Changes to the Delivery of the GTA Mentorship Program}

The main obstacle in scheduling an ongoing GTA professional development program has been arranging the time and location for sessions, both the orientation at the beginning of the academic year and the ongoing workshops throughout the year. The major reasons for scheduling difficulty include GTAs' busy schedules, including graduate coursework and research duties such as data collection, other paid employment (both research assistant and clinical work), and childcare responsibilities. Thus, finding a mutually agreed upon time to schedule the GTA professional development sessions is complicated, especially when faculty members are invited.

Beginning in 2016-2017, instead of scheduling a half-day orientation and 1.5-hour workshops throughout the year, a full-day orientation was offered immediately before the start of the year. This orientation included an overview of the role and introduction to the program, a workshop on accessibility and diversity, a marking and assessment session, and a short focus group discussion between GTAs and faculty regarding GTA and faculty lived experiences, which was intended as on-the-spot information sharing. The senior TA developed the full-day orientation by taking into consideration feedback from faculty and the previous year's GTAs.

The rationale for scheduling a full-day orientation, rather than the more distributed format used in previous years, was related to fewer scheduling conflicts at the start of the year for GTAs, and the ease of arranging full-day child-care or absence from work. The 2016-2017 orientation was attended by the majority of GTAs $(n=7 / 9)$ with few complaints regarding this new scheduling.

\section{Program Evaluation}

The program is evaluated at the end of each academic term (i.e., in December and April) by one or two informal one-hour feedback sessions per year. The senior TA facilitates these 
sessions, and all GTAs are invited to attend, with informal feedback collected from GTAs unable to attend. Some of the feedback from the TAs over the past few years has included the following: (1) they find the one-on-one mentorship by their faculty leads and the one-day orientation to be very useful for understanding how to build and accomplish their personal learning goals as GTAs; (2) they voiced that the student evaluations at the end of their GTA contract were very helpful in planning for improvements and having positive opportunities for learning; and (3) GTAs found the sessions on cultural safety in the classroom very beneficial and practical for their work with large and diverse undergraduate classes.

Even with these adjustments to the scheduling for the full-day orientation session, not all GTAs were able to attend in person or via teleconference. Because of this obstacle, GTAs identified a need for an online component to the TA professional development. It was suggested this approach could include content from previous workshops, the GTA handbook, and online asynchronous discussion groups. These groups would allow experienced GTAs to mentor novice GTAs. Finally, adopting an online platform for the orientation and workshops would allow videoconference capabilities and more interaction between attendees at the School of Nursing and attendees at off-campus locations, relative to the current teleconferencing system. Other institutions have had success at providing online resources for GTAs, and this school of nursing in western Canada's graduate program has a website with some additional helpful materials.

In developing our GTA mentorship program, we drew from theories of experiential learning (Kolb \& Fry, 1974), andragogy (Knowles, 1984), situated learning (Lave \& Wenger, 1990), and cultural safety. Accordingly, in the GTA program evaluation, we conducted needs assessments in which we elicited what knowledge and skills GTAs felt they required to be effective teachers. This was evaluated, both formally and informally, to establish whether the participants felt these needs were met. We organized group feedback sessions at the end of each term, facilitated by the senior TA, and encouraged a community of practice in which novice and experienced GTAs could voice how the GTA mentorship program met their learning needs to become effective educators.

\section{Implications for the Future}

Over the course of offering the GTA professional development program at this School of Nursing in western Canada, GTAs, faculty, and the senior TA and director have developed recommendations for how the program can be adapted to meet GTA's needs. These include more (1) online content, (2) online synchronous and asynchronous communication, (3) opportunities for mentorship from more experienced GTAs and faculty, and (4) standardized methods of assessing GTAs' needs and eliciting feedback.

One growing need is the desire to make additional online resources available for GTAs to assist them in performing their duties. Given that the workshop topics vary from year to year, there could be an online repository of workshop materials. In recent academic years, the senior TA has also worked to develop online materials to enrich GTAs' learning and resources.

Another need, partially met thus far, is to provide additional online and virtual formats of communication. GTAs will on occasion attend workshops and professional development via teleconferencing. However, if online platforms were used to a greater extent, more GTAs could attend these sessions. This modality would also allow GTAs to communicate with mentors (both more experienced TAs and faculty) synchronously. There could also be the opportunity via an 
online course delivery platform for GTAs to participate in asynchronous communication, both with each other and with mentors.

A final identified need is to develop more comprehensive, standardized, and systematic methods of assessing GTAs' needs and evaluating whether the programs' objectives are met. Currently, needs are assessed in a more informal manner, and while the senior TAs chairs feedback sessions regarding to the program, we have determined that it would be more desirable to have a standardized, empirical method of eliciting feedback. Such a method would also be consistent with the university entity providing external funding's expressed expectation that a formal program evaluation of GTA mentorship programs be conducted. A recommended formal method of eliciting GTAs' feedback would be to develop a standardized, online, quantitative needs assessment that is distributed to GTAs at the end of the academic year. This assessment could also include a quantitative section on whether the objectives for the program at the beginning of the academic year were met.

\section{Conclusion}

In conclusion, there is a clear and growing need for nursing faculty to support graduate nursing students in the development of their pedagogical/andragogical knowledge and effective teaching skills. However, little has been published regarding the best approaches or evaluation of such mentorship programs. Mixed methods evaluative research is needed to evaluate the effectiveness of programs and to monitor how the program evolves to meet the changing needs and demands of GTAs and of nursing academia in the development of competent nursing educators. Developing more systematic and standardized methods of eliciting GTA feedback, and ensuring that program objectives are met, would be desirable moving forward. Nonetheless, we have demonstrated that such a GTA professional development program is useful in addressing the need for postsecondary nursing educators in Canada. 


\section{References}

Blouin, D., \& Moss, A. (2015). Graduate student teacher professional development: Still relevant (and missing?) 20 years later. Teaching Sociology, 43(2), 126-136.

Browne, A. J., Varcoe, C., Smye, V. L., Reimer-Kirkham, S., Lynam, M. J., \& Wong, S. (2009). Cultural safety and the challenges of translating critically oriented knowledge in practice. Nursing Philosophy, 10, 167-179. https://doi.org/10.1111/j.1466-769X.2009.00406.x

Browne, A. J., Ward, C., Varcoe, C., Fridkin, A., \& Blanchet Garneau, A. (in press). San'yas Indigenous Cultural Safety Training: Promoting anti-racism and health equity in systems and practices. International Indigenous Policy Journal.

Canadian Nurses Association. (n.d.). Tested solutions for eliminating Canada's registered nurse shortage. https://www.cna-aiic.ca/en/nursing-practice/the-practice-of-nursing/healthhuman-resources

Chandler, G. (2005). Growing nurse leaders: An undergraduate teaching assistant program. Journal of Nursing Education, 44(12), 569--72.

Cheng, A., Morse, K. J., Rudolph, J., Arab, A. A., Runnacles, J., \& Eppich, W. (2016). Learnercentered debriefing for health care simulation education: Lessons for faculty development. Simulation in Healthcare, 11(1), 32-40. https://doi.org/10.1097/sih.0000000000000136

Crede, E., Borrego, M., \& McNair, L. (2010). Application of community of practice theory to the preparation of engineering graduate students for faculty careers. Advances in Engineering Education, 2(2), 1-22.

Dragisich, V., Keller, V., \& Zhao, M. (2016). An intensive professional development program for effective teaching assistants in chemistry. Journal of Chemical Education, 93, 12041210.

Garrett, B. (2020). Learning theories. In P. Bradley \& K. Page-Cutrara (Eds.), The Role of the Nurse Educator in Canada (Chapter 2). Canadian Association of Schools of Nursing.

Harris, G., Froman, J., \& Surles, J. (2009). The professional development of graduate mathematics teaching assistants. International Journal of Mathematical Education in Science and Technology, 40(1), 157-172.

Knowles, M. (1984). Andragogy in action. Jossey-Bass

Kolb, D. A., \& Fry, R. E. (1974). Toward an applied theory of experiential learning (Working Paper No. 732-74). Sloan School of Management, MIT.

Komarraju, M. (2008). A social-cognitive approach to professional development teaching assistants. Teaching of Psychology, 35(4), 327-334.

Lave, J., \& Wenger, E. (1990). Situated learning: Legitimate peripheral participation. Cambridge University Press.

Li, Y., Turinetti, M., \& Fang, D. (n.d.). Special survey on vacant faculty positions for academic year 2018-2019. American Association of Colleges of Nursing. https://www.aacnnursing.org/Portals/42/News/Surveys-Data/Vacancy18.pdf 
Moore, D. (2005). Preparing graduate students to teach statistics. American Statistician, 59(1). $1-3$.

Murray, T. (2018). Our iceberg is melting. Journal of Nursing Education, 57(10), 575-576. https://doi.org/ 10.3928/01484834-20180921-01

Papps, E., \& Ramsden, I. (1996). Cultural safety in nursing: The New Zealand experience. International Journal for Quality in Health Care, 8(5), 491-497.

Pentecost, T., Langdon, L., Asirvatham, M., Robus, H., \& Parson, R. (2012). Graduate teaching assistant professional development that fosters student-centered instruction and professional development. Journal of College Science Teaching, 41(6), 68-75.

Prieto, L., \& Scheel, K. (2008). Teaching assistant professional development in counseling psychology. Counselling Psychology Quarterly, 21(1), 49-59.

Provincial Health Services Authority. (2019). [Province of XX] San'yas Indigenous Cultural Safety (ICS) professional development program. http://www.sanyas.ca/training/britishcolumbia

Russell, J. (2008). An examination of kinesiology GTAs' perceptions of an instructional development and evaluation model. Physical Educator, 65(1), 2-20.

Sheng, R., Goldie, C. L., Pulling, C., \& Luctkar-Flude, M. (2019). Evaluating student perceptions of a multi-platform classroom response system in undergraduate nursing. Nurse Education Today, 78, 25-31. https://doi.org/ 10.1016/jnedt.2019.03.008

Smye, V. L., \& Browne, A. J. (2002). "Cultural safety" and the analysis of health policy affecting Aboriginal people. Nurse Researcher, 9(3), 42.

Truth and Reconciliation Commission of Canada. (n.d.). Our mandate. http://www.trc.ca/aboutus/our-mandate.html

University (2020). Information Security Policy, Standards, and Resources: Information Security Standards. https://cio.ubc.ca/information-security/information-security-policy-standardsand-resources

University Board of Governors (2019). Acceptable Use and Security of UBC Electronic Information and Systems.

http://universitycounsel-2015.sites.olt.ubc.ca/files/2019/08/Information-SystemsPolicy_SC14.pdf

University \& Union (2019). Collective Agreement. https://cupe2278.ca/

Varcoe, C. \& Browne, A.J. (2015). Culture and cultural safety: Beyond cultural inventories. In Fundamentals: Perspectives on the Art and Science of Canadian Nursing, 216-231. C. D. Gregory, L. Raymond- Seniuk, L. Patrick and T. Stephen (Eds.). Philadelphia: Lippincott Williams \& Wilkins.

Ward, M., Knowlton, M. C., \& Laney, C. W. (2018). The flip side of traditional nursing education: A literature review. Nurse Education in Practice, 29, 163-171. https://doi.org/https://doi.org/10.1016/j.nepr.2018.01.003

Winston, I. (2011). Nursing shortages a national concern. Canada.com. http://www.canada.com/health/Nursing+shortages+national+concern/4288871/story.html 